\title{
RECRUTAMENTO E SELEÇÃO DE RECURSOS HUMANOS EM UM HOSPITAL PSIQUIÁTRICO DE UM MUNICÍPIO PAULISTA*
}

\author{
Luciano Mazon ** \\ Maria Auxiliadora Trevizan***
}

\begin{abstract}
MAZON, L.; TREVIZAN, M.A. Recrutamento e seleção de recursos humanos em um hospital psiquiátrico de um município paulista. Rev.latino-am.enfermagem, Ribeirão Preto, v. 8, n. 4, p. 81-87, agosto 2000.
\end{abstract}

O objetivo deste trabalho é divulgar experiência de recrutamento e seleção de recursos humanos em um hospital psiquiátrico de Ribeirão Preto. Trata-se de um hospital filantrópico que possui cento e quatro leitos, presta assistência a pacientes com problemas mentais, bem como farmacodependentes, e atualmente conta com oitenta e quatro funcionários, apresentando um alto "turnover" de pessoal nos diversos setores. Como estagiário desta instituição percebemos que o alto "turnover" prejudica o desenvolvimento das atividades no âmbito da organização e em conseqüência a melhor assistência aos clientes. Assim sendo, fomos convidados a integrar uma equipe que se responsabilizou pelo recrutamento e seleção de recursos humanos desta entidade. Após estes processos, com o devido acompanhamento pelos responsáveis dos respectivos setores, a finalidade da nossa intervenção é a redução do "turnover", maior engajamento institucional pelo pessoal, mais sincronia entre os funcionários, diminuição de gastos e de atividades burocráticas relacionadas a contratação e demissão de pessoal, reduzindo o trabalho operacional e implementando mais o trabalho assistencial de planejamento, orientação, execução e avaliação.

UNITERMOS: recrutamento pessoal, seleção de pessoal, recursos humanos em hospital

\section{INTRODUÇÃO}

As realidades organizacionais contemporâneas têm procurado cada vez mais liberar a criatividade e a inovação através da adoção de medidas que visem ao desenvolvimento do potencial e da capacidade das pessoas, ou seja, de seu capital humano. Neste sentido os "novos líderes serão pessoas capazes de exprimir uma visão que inspire e fortaleça todos na instituição. Eles se assemelharão mais a xamãs do que a supervisores pessoas que encorajam todos os membros da organização a compartilhar um sonho mutuamente benéfico" (BENNIS, 1994).

Esta perspectiva representa um desafio para o hospital - organização prestadora de serviços, especialmente na esfera da gestão dos recursos humanos, que segundo KARMAN et al.(1995), “...padece de uma falta de interesse evidente." Para eles, qualquer projeto de melhoria e desenvolvimento a ser implementado na organização hospitalar afeta a administração do pessoal nela inserida. Dos objetivos gerais da gestão dos recursos humanos propostos por estes autores, destacamos: “...estabelecer a missão global da gestão dos recursos humanos para com o estabelecimento, que é o de fornecer pessoal em qualidade e quantidades ótimas."

O recrutamento e a seleção constituem-se atividades integrantes desse processo de gestão. Tais atividades envolvem a exploração e a análise do mercado de trabalho tendo em vista a escolha e a dotação de pessoas para a organização. Condizentes com a nova postura institucional, de valorização dos recursos humanos, o recrutamento e a seleção já devem encorajar e incentivar pessoas criativas e inovadoras para que se tornem forças na igualdade e na diversidade e, sobretudo, que saibam compartilhar.

Como aluno do $4^{\circ}$ ano da Faculdade de Economia, Administração e Contabilidade, Campus de Ribeirão Preto, da Universidade de São Paulo (FEARP/ USP) e estagiário de um hospital psiquiátrico de um município paulista, desenvolvemos os processos de recrutamento e seleção de recursos humanos nesta instituição. Desta forma, com a autorização da instituição, temos como propósito disseminar essa experiência. Assim, o objetivo deste trabalho é descrever

\footnotetext{
* Trabalho apresentado no $6^{\circ}$ Simpósio de Iniciação Científica da Universidade de São Paulo, Ribeirão Preto, novembro, 1998 ** Graduando em Administração da Faculdade de Economia, Administração e Contabilidade - Campus de Ribeirão Preto da Universidade de São Paulo e Bolsista de Iniciação Científica/CNPq, vinculado ao Projeto Capital Humano da Enfermagem no meio hospitalar: enfoque sobre a liderança do enfermeiro

*** Professor Titular da Escola de Enfermagem de Ribeirão Preto da Universidade de São Paulo, Centro Colaborador da OMS para o desenvolvimento da pesquisa em enfermagem e responsável pelo projeto subvencionado pelo CNPq
} 
procedimento de recrutamento e seleção de pessoal, a partir de perspectiva teórica e de situação vivenciada em hospital psiquiátrico.

Para isso, inicialmente tecemos considerações sobre o hospital em questão, a seguir abordamos teoricamente o recrutamento e seleção, para então, expormos a experiência desenvolvida.

\section{SOBRE O HOSPITAL EM QUESTÃO}

O Sanatório Espírita Vicente de Paulo, Hospital Psiquiátrico, foi fundado em 08/02/1946, sendo uma entidade filantrópica que presta relevantes serviços à comunidade na área da Saúde Mental, possuindo cento e quatro leitos, cujos programas objetivam reintegrar essas pessoas à família e à sociedade.

Atualmente atendendo às necessidades da reforma psiquiátrica e a demanda de clientela da região, há dois anos mudou o atendimento, que focalizava os doentes mentais agudos, para dois serviços diferentes:

1. Presta atendimento a doentes mentais crônicos moradores, homens e mulheres adultos, num processo de ressocialização dos mesmos. Estes usuários são pessoas que viveram praticamente a vida toda abandonados pelas famílias, perdendo a identidade e considerados fora de terapia pelos profissionais que os atendiam em suas necessidades fisiológicas. $O$ processo de ressocialização destes doentes envolve uma equipe multidisciplinar formada por médicos psiquiátricos, assistentes sociais, psicólogos, terapeutas ocupacionais, enfermeiros e auxiliares de enfermagem cujo objetivo é resgatar os seus direitos de cidadania.

Desta forma, depois de dois anos, quase todos os pacientes já tiveram localizadas as famílias, providenciados seus documentos e num desenvolvimento crescente, participam da vida, fora do hospital. Saem para passeio, acompanhados por profissionais e/ou voluntários e até mesmo sozinhos, dependendo de cada caso. Nos passeios, são incluídas visitas a clubes, circo, teatro, museus, supermercados e/ou compras variadas, pois neste processo de resgate de direitos, cerca de $30 \%$ dos internados já está recebendo seus benefícios do Estado e aprendendo a lidar com o dinheiro, sendo que cada um tem sua conta bancária, movimentada sob orientação da assistente social que constitui a equipe e controlada pela contabilidade e tesouraria do hospital. Os benefícios financeiros pertencem ao paciente e são usados para atendimento de suas necessidades, compra de um objeto pessoal, almoços "fora", etc. Se o cliente for transferido para outro hospital, ou, o que é nosso objetivo, for para a casa, o mencionado benefício o acompanhará para dar melhores condições de sustento. Estes pacientes passam por um novo aprendizado como se fossem nossos filhos - aprendendo desde a se vestir, se cuidar, até como se portar diante das outras pessoas. Isto inclui aulas de como lavar suas roupas, cozinhar, escovar os dentes, etc. É um desafio que está dando certo.

Quem está custeando este trabalho?

O SUS em parte, porque a tabela regulamentada pelo mesmo está tão defasada que hoje, praticamente alguns hospitais estão deixando de atender ao sistema. No caso do hospital em estudo, sua receita é proveniente do SUS; entretanto, como esta receita não corresponde à despesa da instituição, um trabalho conjunto de seus profissionais e voluntários com a população, angaria recursos para maximizar a receita, além de contar com doações de entidades de serviços e produtoras de bens.

2. O outro serviço que este hospital presta está relacionado com o atendimento a adolescentes e adultos farmacodependentes, ou seja, dependentes de droga, álcool ou ambos. É um atendimento sem internação, com um programa realizado por uma equipe de profissionais de nível universitário na maioria. Há os pacientes que participam de oficinas terapêuticas, atividades de grupos ou até mesmo de atendimentos individuais, dependendo da situação do cliente.

Os atendimentos individuais ou grupais incluem programas de apoio às famílias ou responsáveis, com constante assistência e esclarecimento, objetivando tratar a causa do problema. Este serviço foi comprado pela Prefeitura Municipal nas bases da tabela SUS, o qual repassa os recursos à Prefeitura.

Nestes dois anos o atendimento aos farmacodependentes cresceu e tem sido um sucesso, prova é que o Conselho Municipal da Saúde e a Comissão do Movimento pela Luta Anti-Manicomial aprovaram contrato novo entre Prefeitura e Sanatório estendendo a vigência deste contrato para mais um ano (podendo ser prorrogado por iguais e sucessíveis períodos, limitados a 60 meses). Hoje já são muitos os recuperados que se integraram no mercado de trabalho mas, de alguma forma, ainda sentem a necessidade desse apoio terapêutico e, assim continuam freqüentando o serviço.

Em relação à administração do hospital, algumas transformações também foram feitas nesse período: a diretoria, com um terço do conselho reformado, integrando voluntários ativos, resolveu empreender uma reestruturação no hospital, e a primeira medida tomada foi submetê-lo a uma auditoria para se obter um levantamento de tudo o que estava acontecendo neste setor, e nada melhor do que alguém fora da instituição, sem nenhum interesse de favorecer uma das partes, para desenvolver este trabalho. Assim sendo, esta auditoria foi realizada pela Júnior-FEA, empresa de Consultoria \& Planejamento, que é uma associação civil sem fins lucrativos, integrada e gerida pelos alunos da FEARP/ 
USP, orientada tecnicamente pelo corpo docente desta Faculdade, atuando nas áreas de Economia, Administração e Contabilidade.

A Júnior-FEA detectou muita desorganização na esfera administrativa, erros contábeis e de controle financeiro e uma notável desordem na área de recursos humanos. Desta forma, a proposta de renovação e modernização administrativa foi tomada nos seguintes termos: “... o objetivo é proporcionar melhorias e soluções, baseando-se nas disposições integrantes do Regulamento da Instituição, enfatizando aquilo que cabe à contabilidade propriamente dita. Também uma análise administrativa da estrutura organizacional, bem como organização e métodos nas práticas administrativas"(JÚNIOR-FEA, 1998).

No momento, em caracter de experiência, a administração do Sanatório está sendo realizada por três alunos do $4^{\circ}$ ano da FEARP/USP (Faculdade de Economia, Administração e Contabilidade da Universidade de São Paulo, campus de Ribeirão Preto), sendo dois alunos do Curso de Ciências Contábeis e um do Curso de Administração de Empresas. A proposta desta administração, além de se fundamentar nas recomendações do grupo auditor, é efetivar um gerenciamento transparente em relação aos recursos humanos e materiais, aos serviços prestados, com constantes prestação de contas, à população e autoridades que sustentam esta Casa. Os alunos responsáveis por essa administração intercambiam idéias e experiências com o novo Diretor Administrativo do hospital, que supervisiona os trabalhos destes estagiários.

É idéia da instituição integrar no seu quadro de pessoal o aluno que mais e melhor se qualificar e se identificar com os seus objetivos, passando então a assumir a responsabilidade pela administração do Sanatório, renovando os estagiários, para que a Instituição não perca o vínculo com a Faculdade.

Além desta reforma de base de qualquer organização, que é na parte administrativa, estes novos colaboradores estão fazendo uma reestruturação geral em todo o hospital, o que está relacionado com a mudança geral do organograma existente no momento.

A idéia de transformação do organograma vigente está baseada em uma maior descentralização, procurando delegar autoridade e responsabilidade aos serviços técnicos e, desta forma, torná-los capazes de se organizarem tendo em vista a dinâmica do trabalho. Esta descentralização propicia às instâncias administrativas mais elevadas, no caso a estes novos agentes de mudança, mais tempo para reflexão e ação que visem, constantemente, ao aperfeiçoamento e ao desenvolvimento do hospital.

Há também, relacionado com o processo de ressocialização dos pacientes, a construção da Vila de Residências Terapêuticas que é o novo objetivo a longo prazo deste hospital, tendo como título, Horizontes sem Fronteira, que visará a "seqüência do processo de adequação do Sanatório às novas diretrizes da reforma psiquiátrica, cujo desfecho, a longo prazo, deve ser o fim dos manicômios"(PROCESSO..., 1998).

É oportuno ressaltar que todos estes trabalhos desenvolvidos estão sob a direção da principal responsável por estas mudanças que é a atual presidente da instituição. Sua visão, determinação e apoio perseguem a meta de transformar o Sanatório num modelo para o Brasil.

\section{RECRUTAMENTO E SELEÇAO DE CAPITAL HUMANO - ABORDAGEM TEÓRICA}

As mudanças em nível internacional quanto a sua natureza econômica, social e tecnológica são constantes, sendo elas, na maioria das vezes, mais rápidas do que a própria vivacidade de uma organização. Tais mudanças só serão acompanhadas pelas organizações se houver uma administração voltada para a gestão de recursos humanos, visto que a continuidade de sua existência sempre buscando a excelência será determinada pela qualidade agregada aos seus produtos ou serviços, tendo como base pessoas motivadas e com alto nível de qualidade pessoal e profissional.

Nossa realidade empresarial apresenta elevados índices de rotatividade ("turnover"), absenteísmo, acidentes de trabalho, problemas com qualidade dos processos, desperdício de tempo e de materiais, condições de trabalho inadequadas e relações de trabalho insatisfatórias. Esses fatores estão diretamente relacionados à administração de recursos humanos, e esta deverá estar continuamente atenta para que estes problemas existentes não agravem cada vez mais os destinos da organização.

Precisamos mudar este cenário e, para isto, é necessário administrar recursos humanos de forma ampla, com um planejamento adequado ao longo de todo o tempo em que o funcionário fizer parte da organização. É preciso considerar, sobretudo, que estes recursos tão importantes das empresas sejam não apenas o pessoal que nelas trabalha, mas sim a própria organização. Desta forma, é necessário um cuidado especial para escolher quem serão estas pessoas que integrarão esta equipe, e o primeiro passo a ser dado é o recrutamento e a seleção deste pessoal.

\section{RECRUTAMENTO}

É um processo organizacional que "convida" 
pessoas que se encontram no mercado de mão-de-obra para participarem de um processo de seleção da empresa, tendo como finalidade atrair um número satisfatório, e adequado à organização, de profissionais necessários para uma futura ocupação de um cargo/função na empresa. Este processo deve sempre estar atento ao tempo dispendido para esta ação, aos custos e à otimização para a fase posterior que é a seleção.

Muitas organizações não dispendem muita atenção e cuidado no processo de recrutamento e seleção de pessoal, tendo depois que suportar problemas significantes no futuro da organização, problemas estes que serão discutidos mais adiante. Esta desatenção é explicada por várias maneiras, uma das mais comuns está baseada "na crença de que os recursos humanos são abundantes, sendo facilmente repostos ou atraídos"(DUTRA, 1990).

O Recrutamento, segundo CHIAVENATO (1995), pode ser dividido em três formas: interno, externo ou misto.

- O recrutamento interno é feito na própria empresa. Quando surge uma vaga, seu preenchimento se dá através de remanejamento de empregados, por meio de promoção, transferência ou transferência com promoção. - O recrutamento externo é aquele feito fora da organização, isto é, a empresa busca candidatos disponíveis no mercado, ou atuantes em outras empresas. - O recrutamento misto é a conseqüência de um recrutamento interno, que provavelmente irá gerar uma nova vaga desta pessoa transferida, devendo assim se fazer um recrutamento externo.

\section{Recrutamento interno}

O primeiro passo na procura de pessoal é o recrutamento dentro da empresa, que não deve ser confundido como o recrutamento através dos funcionários. Em resumo, recrutamento interno é "um processamento (ou transformação) de recursos humanos"(CHIAVENATO, 1995). Esta política, se adotada efetivamente, oferece diversas vantagens que mais freqüentemente superam suas limitações, quais sejam: é a fonte mais próxima e rápida; menores custos de recrutamento, seleção e treinamento do pessoal; já se conhece o desempenho anterior do funcionário; resulta numa maior segurança e validade quanto ao funcionário; estimula-se a preparação para promoção, criando um clima sadio de progresso profissional; aumenta-se a moral e motivação dos funcionários; motiva para boas performances; melhoram-se as relações públicas com os funcionários; e desenvolve uma positiva e sadia competição entre o pessoal. Por outro lado, são suas desvantagens: pode causar conflito de interesses; ressentimento dos não promovidos; e recrutamento interno reduz a criatividade e a inovação do trabalho.

\section{Recrutamento externo}

Quando uma organização adota uma política de recrutamento externo, subentende-se que, ou ela possui um "turnover" excessivo, ou ela não acredita em seu pessoal, por não mantê-lo capacitado, ou devido a uma grande expansão em seus negócios. Porém, nem sempre o recrutamento externo é menos favorável que o recrutamento interno.

O recrutamento externo é preferencial no caso de auxiliares do nível mais baixo, operários não qualificados, funções raras e muito especializadas, trainees de gerência. Já o recrutamento interno deve ser usado principalmente para buscar: chefes dos primeiros níveis de supervisão (chefes de seção, de grupo, líderes, subchefes, mestres, etc).

As fontes externas de recrutamento podem ser: anúncios de emprego em jornais, revistas ou rádios; agências de emprego; recomendações dos funcionários; escolas e universidades; sindicatos e associações de classes; cartazes nos locais de maior tráfego; centros recrutadores; arquivo de propostas anteriormente preenchidas; e contatos com outras organizações.

As vantagens do recrutamento externo são: criação de novas idéias e melhoramentos; aumento do nível de conhecimento e habilidades não disponíveis na organização atual; e reduz custos de desenvolvimento de pessoal, já que a pessoa contratada do mercado já está teoricamente qualificada. As desvantagens do recrutamento externo são: é mais caro; a margem de erro é maior; maior tempo de adaptação; pode trazer atitudes que não estão de acordo com a cultura da organização; dificuldade de adequação entre empregado e organização (cultura, hábitos, etc), havendo a necessidade de um período maior de ajustamento; e menor moral e comprometimento dos empregados antigos que se sentem desvalorizados no desempenho de suas funções e não se esforçam para melhorar sua performance.

\section{Recrutamento misto}

Segundo CHIAVENATO (1995), uma empresa nunca faz um recrutamento interno sem fazer um recrutamento externo. Um sempre deve complementar o outro, pois quando um funcionário muda de posição, automaticamente um cargo ficará vago. O recrutamento misto pode ser adotado por três funções: inicialmente recrutamento externo seguido de recrutamento interno; inicialmente recrutamento interno seguido de recrutamento externo; e recrutamento externo e recrutamento interno, concomitantemente. 
SELEÇÃO

A seleção tem como objetivo escolher, entre os candidatos atraídos pelo recrutamento, aqueles que correspondem ao perfil do cargo desejado pela empresa, "visando a manter ou aumentar a eficiência e desempenho do pessoal"(CHIAVENATO, 1995). Em ambos os casos, recrutamento e seleção, é feita uma análise de aspectos profissionais e pessoais dos candidatos, tendo em vista a adequação ao cargo. Portanto, quando a seleção é bem feita, resultará em uma alta produtividade, retorno ao investimento dispendido, ajudando a empresa cumprir seus planos e objetivos.

No geral, o processo de seleção busca chegar a uma conclusão de análise de conhecimentos, habilidades, atitudes, personalidade e outros fatores que estão ligados à adaptação na organização como sexo, porte físico, estatura, endereço, posse de um carro, idade, etc.

Muitas organizações diferem em complexidade de seus sistemas de seleção. Algumas fazem uma decisão estratégica para selecionar rapidamente e sem grandes custos e outras tomam uma decisão de escolher a melhor pessoa possível, tendo um elaborado e, algumas vezes, custoso sistema de seleção. Portanto, o processo de seleção deve ser um critério personalizado de trabalho, variando de empresa para empresa.

Em um contexto geral, o processo de seleção pode ser esquematizado como segue-se abaixo: análise curricular, testes, entrevista, e verificação de referências.

\section{Análise curricular}

Corresponde a uma das primeiras fases do processo de seleção, e visa fazer uma pré-seleção dos candidatos, eliminando os que não tenham os prérequisitos desejados pela organização.

Após feita uma pré-seleção, faz se uma análise cuidadosa do currículo de cada candidato para que as próximas fases sejam direcionadas sobre os conhecimentos, habilidades e atitudes de cada um.

\section{Testes}

Os testes são considerados como uma das mais importantes fases deste processo, já que eles definem quem serão os poucos candidatos que irão para a fase final da seleção, que é a entrevista. Os tipos de testes utilizados podem ser: conhecimentos gerais e específicos; de idiomas; grafológicos; testes de habilidades mentais; prova de trabalho; teste de honestidade e integridade; e dinâmica de grupo.

\section{Entrevista}

É considerada como uma das mais importantes etapas de um processo de seleção, e tem como finalidade obter informações pessoais e profissionais, além de esclarecer e aprofundar questões contidas nos formulários preenchidos (solicitação de emprego) e no currículo. A entrevista constitui-se num momento adequado para verificar as experiências nos empregos anteriores, observar o temperamento, o interesse do candidato e seus aspectos pessoais relacionados com o cargo a ser preenchido, ou seja, comportamento durante a entrevista, higiene pessoal, vestuário, etc.

Segundo DESSLER (1998), a entrevista é de longe o procedimento mais amplamente usado no processo de seleção, pois o contato pessoal é uma das melhores formas de se extrair conclusões da pessoa que irá estar inserida no processo de trabalho da organização.

\section{Verificação de referências}

Nesta etapa, procura-se obter informações profissionais e pessoais, visando comprovar a veracidade dos dados fornecidos, e aprofundar o nível de informações referentes ao desempenho profissional dos candidatos nos empregos anteriores. Podem ser levantadas através de contato telefônico, pessoalmente ou carta de referência.

Além desses procedimentos o candidato selecionado será submetido ao exame físico, cuja finalidade é: cumprir a exigência legal; comprovar a sanidade física do candidato para o cargo; e comprovar o estado geral de saúde e eventuais doenças ou deficiências da pessoa;

O exame físico traz as seguintes vantagens para a empresa: prevenir ausências por doença; reduzir possibilidades de acidentes; e obter maiores rendimentos.

\section{A EXPERIÊNCIA DESENVOLVIDA}

Contando hoje com oitenta e quatro (84) funcionários, percebemos a existência de um alto "turnover" de pessoal nos diversos setores do hospital. Conforme dados obtidos, de janeiro de 1997 a setembro de 1998 foram demitidos 38 funcionários de vários setores. No mesmo período foram admitidos 44 funcionários, o que nos dá uma rotatividade de cerca de 4 funcionários por mês.

Como estagiário desta instituição percebemos que o alto "turnover" prejudica o desenvolvimento das atividades no âmbito da organização e em conseqüência a qualidade da assistência aos clientes. Assim sendo, fomos convidados a integrar uma equipe que se responsabilizou pelo recrutamento e seleção de recursos humanos desta entidade, na tentativa de solucionar o problema. 
Esta equipe, com a ajuda e o devido acompanhamento dos responsáveis pelos respectivos serviços, atuou no sentido de reduzir este "turnover".

A conseqüência da redução do "turnover" é, primeiramente, a diminuição de gastos e das atividades burocráticas relacionadas com a contratação e demissão de pessoal. $\mathrm{O}$ grande tempo dispendido pelo funcionário da área de recursos humanos para desenvolver essas atividades, sem contar o utilizado no recrutamento e na seleção, não permitindo assim que o mesmo se dedique mais seu tempo para trabalhar com novas idéias com a intenção de agregar valores para a entidade.

Primeiramente, a equipe responsável pelo recrutamento e seleção de pessoal, após já ter implantado um sistema de organização e métodos na parte administrativa, elaborou uma reestruturação e adequação do banco de dados de todos os currículos que lá se encontravam sendo eles analisados um a um, procedendose a uma divisão deste arquivo para que cada setor profissional fosse devidamente separado como psicólogos, terapeutas ocupacionais, enfermeiros, médicos, etc.

Apesar de encontrarmos currículos com data de expedição de mais de dez anos, e que teoricamente estariam totalmente defasados, foi tomado o cuidado de não se desfazer destes, já que eles poderiam ser reaproveitados num novo processo de seleção. Assim, foi feita uma tentativa de contato com todos para saber do seu interesse em trabalhar em nossa entidade e em caso positivo, de atualizar seu currículo. Resultou desta etapa a eliminação de aproximadamente $90 \%$ dos currículos por nós classificados como defasados, sendo que em boa parte deles nem o telefone mais existia.

Com esta primeira fase concluída, a de organização, ficou mais otimizado o processo de recrutamento e seleção de novos funcionários. Em seguida, expediu-se orientação aos chefes de cada setor do hospital no sentido de comunicarem a administração, sempre que houver a necessidade da contratação de um novo funcionário para assim serem tomadas as primeiras providências do processo.

O processo de recrutamento adotado pela equipe foi o externo usando as seguintes fontes: anúncios nos jornais, recomendações dos funcionários e arquivos de propostas anteriores preenchidas. Aproximadamente cinqüenta (50) candidatos se apresentaram em conseqüência dos anúncios nos jornais e das indicações de funcionários da instituição. Destes, após análise dos currículos, vinte e três (23) candidatos foram submetidos à entrevista.

As entrevistas foram iniciadas pela equipe, juntamente com o responsável do respectivo setor, quando de posse dos currículos dos vinte e três (23) préselecionados.

Os procedimentos utilizados foram: análise curricular, entrevista e verificação de referências.

Dos vinte e três (23) profissionais que se submeteram à entrevista, a equipe selecionou dez (10) candidatos. Foram efetuadas verificações de referências e após resultado positivo, os dez (10) profissionais foram indicados para os cargos, e já estão vinculados ao hospital, exercendo as seguintes funções: auxiliares de enfermagem (3), médico psiquiatra (2), médico (1), terapeuta ocupacional (1), técnico em enfermagem (1), auxiliar de cozinha (1) e serviçal de limpeza (1).

\section{CONSIDERAÇÕES FINAIS}

As novas propostas de trabalho em vigor nesta entidade, ou seja, orientação mais profissional e mais rigorosa no recrutamento e seleção, interação mais efetiva entre a administração e os chefes de setores e destes com os colaboradores, empenho e compromisso da diretoria visando a excelência do trabalho, interesse em ouvir os funcionários a respeito das atividades que desempenham e das condições de trabalho, interesse em ouvir clientes, têm como finalidade a conciliação das necessidades e capacidades do pessoal com a melhor assistência ao cliente, tendo em vista a qualidade do serviço prestado. Enfim, o que tem fundamentado estas novas propostas é a necessidade de alcance dos objetivos da organização e dos recursos humanos nela inseridos. Desta forma, a equipe acredita que a médio prazo haverá redução do "turnover" e assim, será possível diminuir o trabalho operacional de contratação e demissão de pessoal e desta forma propiciar mais tempo àquele funcionário para desenvolver o trabalho de planejamento, organização, orientação, direção e avaliação dos recursos humanos.

Convém salientar que não é só o trabalho administrativo que se beneficiará com estas medidas. Também o trabalho assistencial será favorecido pois, com a minimização do "turnover" e com a permanência de mais tempo do mesmo funcionário na função, conseqüentemente irá se perceber um maior engajamento institucional e uma maior sincronia entre o pessoal, que resultará em benefício para o cliente.

\section{RECRUITMENT AND SELECTION OF HUMAN RESOURCES IN A PSYCHIATRIC HOSPITAL AT A MUNICIPALITY IN THE STATE OF SÃO PAULO}


the city of Ribeirão Preto, a philanthropic institution with one hundred and four beds that assists pharmaco-dependent patients with mental problems. It presently has eighty-four employees and a high staff turnover in different sectors. As trainees, we realized that the high turnover impaieds the development of activities at the organization as well as prevented a better care delivery to clients. Therefore, we were invited to integrate a team that was made responsible for the recruitment and selection of human resources for this institution. After these procedures and the respective follow-up by those in charge of different sectors, our purpose is to reduce the turnover, implement larger institutional engagement and more synchrony among employees, reduce expenses and bureaucratic activities related to hiring and laying off personnel, reduce operational work and implementing more assisting activities in terms of planning, orientation, execution and evaluation.

KEY WORDS: recruitment, personnel selection, hospital personnel

\section{RECLUTAMIENTO Y SELECCIÓN DE RECURSOS HUMANOS EN UN HOSPITAL PSIQUIÁTRICO DE UN MUNICIPIO PAULISTA}

El objetivo de este estudio es divulgar la experiencia de reclutamiento y selección de recursos humanos en un hospital psiquiátrico de Ribeirão Preto. Se trata de un hospital filantrópico que posee ciento y cuatro camas, presta asistencia a pacientes con problemas mentales, así como también a famacodependientes, y actualmente cuenta con ochenta y cuatro funcionarios, presentando un alto "turnover" de personal de diversos sectores. Como alumnos practicantes en esta institución percibimos que el alto "turnover" perjudica el desarrollo de actividades en el ámbito de la organización y en consecuencia la mejor asistencia a los clientes. Siendo así, fuimos invitados a integrar un equipo que se responsabilizó por el reclutamiento y selección de recursos humanos de esta entidad. Después de esos procesos, con el debido acompañamiento de los responsables por los respectivos sectores, la finalidad de nuestra intervención es la reducción del "turnover", mayor compromiso institucional por el personal, más sincronía entre los funcionarios, disminución de los gastos y actividades burocráticas relacionadas con la contratación y demisión de personal, reduciendo el trabajo operacional e implementando más trabajo asistencial de planeación, orientación, ejecución y evaluación.

TÉRMINOS CLAVES: reclutamiento, selección de personal, recursos humanos hospitalarios

\section{REFERÊNCIAS BIBLIOGRÁFICAS}

01. BENNIS, W. Apresentação. In: PINCHOT, G.; PINCHOT, E. O poder das pessoas: como usar a inteligências de todos dentro da empresa para conquista de mercado. Trad. Ivo Korytowiski. Rio de Janeiro: Campus, 1994. p.xix.

02. CHIAVENATO, I. Recursos humanos. 3. ed. São Paulo: Atlas, 1995.

03. DESSLER, G. Human resource management. 7. ed. New Jersey: Prentice Hall, 1998.

04. DUTRA, J.S. A função recrutamento e seleção como ângulo privilegiado de análise da gestão de RH. In: ANPAD - ASSOCIAÇÃO NACIONAL DE PÓS-GRADUAÇÃO EM ADMINISTRAÇÃO. São Paulo, 1990. Anais. São Paulo: ANPAD, 1990.
05. JÚNIOR-FEA, Consultoria \& Planejamento.

Auditoria, Processo no 10/13, Sanatório Espírita Vicente de Paulo. Ribeirão Preto, 1998.

06. KARMAN, J.M.; MOYSÉS, N.; AUBERT, G. A gestão dos recursos humanos. In: CASTELAR, R. M.; MORDELET, P.; GRABOIS, V. (dirs). Gestão hospitalar: um desafio para o hospital brasileiro. Rennes: Editions ENPS, 1995. p.153154.

07. PROCESSO de ressocialização de pacientes crônicos do Sanatório Espírita Vicente de Paulo terá Vila Terapêutica. A Cidade, Ribeirão Preto, 23 set. 1998. p. 5. 